\title{
The formation of Fe-Cu composite based on bimetallic nanoparticles
}

\author{
A.S. Lozhkomoev ${ }^{\mathrm{a}, *}$, M.I. Lerner ${ }^{\mathrm{a}}$, A.V. Pervikov ${ }^{\mathrm{a}}$, E.V. Naidenkin ${ }^{\mathrm{a}}$, I.P. Mishin ${ }^{\mathrm{a}}$, A.B. Vorozhtsov ${ }^{\mathrm{a}}$, \\ A.S. Apkarian ${ }^{\text {a }}$ D.G. Eskin ${ }^{\mathrm{b}}$ \\ ${ }^{\text {a } I n s t i t u t e ~ o f ~ S t r e n g t h ~ P h y s i c s ~ a n d ~ M a t e r i a l s ~ S c i e n c e ~ o f ~ S i b e r i a n ~ B r a n c h ~ o f ~ R u s s i a n ~ A c a d e m y ~ o f ~ S c i e n c e s . ~ 2 / 4, ~ p r . ~ A k a d e m i c h e s k i i, ~ T o m s k, ~ 634055, ~ R u s s i a ~}$ \\ ${ }^{\mathrm{b}}$ Brunel Univ London, BCAST, Uxbridge, UB8 3PH, Middx, England, United Kingdom
}

\section{A B S T R A C T}

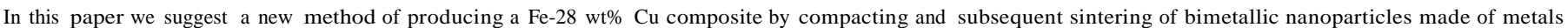

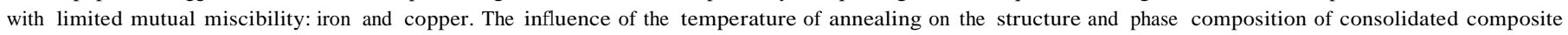

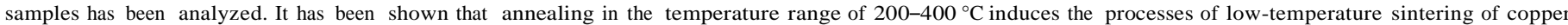

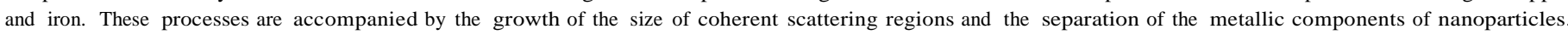

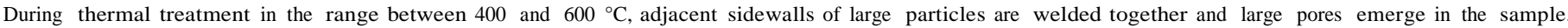

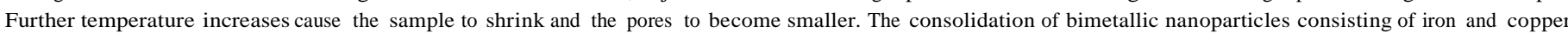

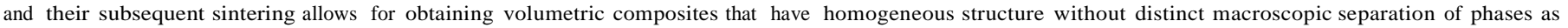
well as high strength characteristics.

\section{Introduction}

Alloys consisting of mutually immiscible metals and those that have limited miscibility in equilibrium conditions are promising materials for a range of engineering applications, thanks to their unique combination of mechanical, electrical and physical properties [1-3]. In regards to some of their physico-mechanical and operational properties, such materials may be superior to traditional alloys of similar purpose. They could be used in the manufacturing of microelectronic devices, wiring items, rocket jet nozzles, etc. [4-8].

The Fe-Cu system is an example of an alloy made of metals with limited mutual miscibility since in equilibrium conditions iron and copper are virtually not intermixing because of mixing enthalpy at temperatures below $700^{\circ} \mathrm{C}[9,10]$. In the meanwhile, volumetric composites of thermodynamically immiscible $\mathrm{Fe}-\mathrm{Cu}$ possess unique mechanical, electrical and magnetic properties and have a wide range of applications [11]. For example, nanocrystal Fe-Cu composites with small copper content exhibit strong magnetostrictive effects [12]. FeeCu catalysts are used to synthesize spirits [13] and to hydrogenate $\mathrm{CO}_{2}$ [14], and Fe-Cu alloys have high surface thermal conductivity and resistance to corrosion [15].

To produce volumetric composites from mutually immiscible metals (or those with limited miscibility), the particle consolidation method is often used, and it relies on traditional approaches of powder metallurgy [16-18]. Here, to increase mutual solubility and obtain metastable phases, preliminary mechanical activation of powders (including nanocrystalline powders) is applied [19,20].

Mixing, compacting and subsequent sintering of nanoparticles of metals with differing properties allows for consolidating mutually immiscible metals for fabricating volumetric composites [17,21]. However, the problematics of the formation of homogeneous mixtures of nanoparticles of two different metals is a complex challenge. Due to their small size, nanoparticles of each of the metals possess high specific surface energy. This determines their high chemical activity and ability to form micron-sized agglomerates [22]. Nanoparticle agglomeration prevents homogeneous mixing of nanopowders of diff erent metals, and such mixing would produce highly homogeneous mixtures of nanoparticles of each of the metals. According to the research, the consolidation of individual nanoparticles (specifically, such highly reactive metals as iron and its alloys) leads to the formation of highly nonhomogeneous microstructures [23].

In this regard, the consolidation of composite bimetallic nanoparticles consisting of such metallic phases is a promising approach to the development of alloys of immiscible metals with homogeneous structures. Consolidation would ensure that the distribution of the components in the alloy is homogeneous.

In the available literature there is no method for forming volumetric composites by sintering bimetallic nanoparticles of mutually immiscible metals (or those with limited miscibility).

In this paper we present the results of the research of the structure, phase composition and microhardness of volumetric samples of a Fe$28 \mathrm{wt} \% \mathrm{Cu}$ alloy. Those were obtained by the compaction of bimetallic

\footnotetext{
* Corresponding author.

E-mail address: asl@ispms.tsc.ru (A.S. Lozhkomoev).
} 


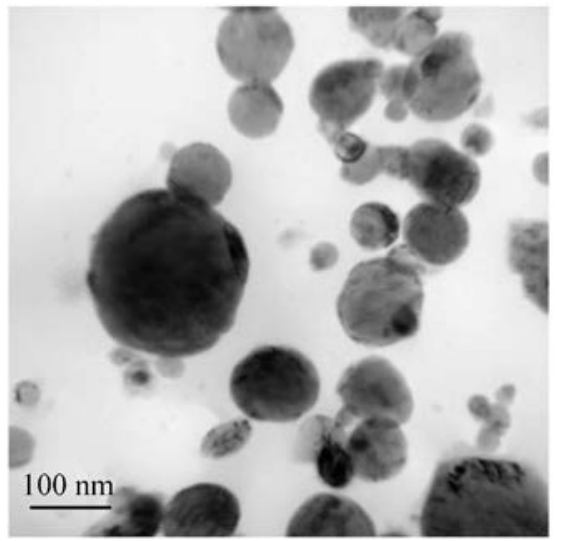

a

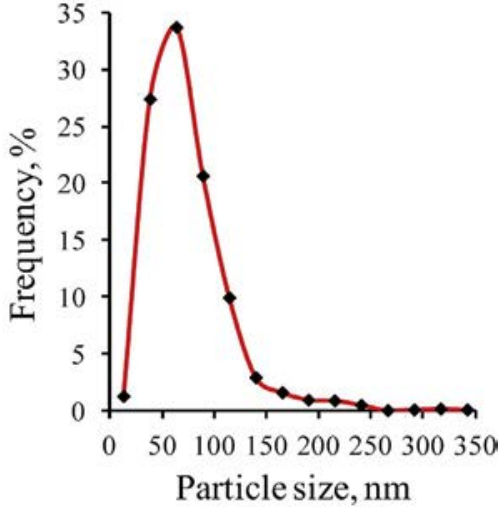

b

Fig. 1. A characteristic image of Fe-28 wt\% $\mathrm{Cu}$ powders (a) and particle size distribution curve (b).

nanoparticles, depending on the temperature of annealing in vacuum.

\section{Experimental}

\subsection{The synthesis of bimetallic nanoparticles}

Bimetallic nanoparticles were synthesized by the electrical explosion of two intertwined wires (copper and iron). The general schematics of the synthesis workflow are provided in Ref. [24]. This method allows for obtaining nanopowders where the content of impurities is determined by the composition of the exploded wires and the impurities in the gas medium surrounding the wires. To synthesize bimetallic nanoparticles, Fe wires (with the diameter of $0.3 \mathrm{~mm}$ and iron content of 99.0 wt. \%) and $\mathrm{Cu}$ wires (with the diameter of $0.2 \mathrm{~mm}$ and copper content of 99.9 wt. \%) were used. The wires were destructed by an incoming pulse of current with the density of $5 \times 10^{7} \mathrm{~A} / \mathrm{cm}^{2}$. The explosion took place in argon atmosphere (99.99 vol\%) at the pressure of $2 \times 10^{5} \mathrm{~Pa}$. The content of copper and iron in the $28 \mathrm{Cu} / 72 \mathrm{Fe}$ wt. $\%$ powders depended on the diameter of the wires that had identical length. After the powder had been obtained, it was passivated by slow air flow into the unit for $48 \mathrm{~h}$.

2.2. The consolidation of bimetallic nanoparticles and subsequent annealing of the samples

Nanoparticle consolidation was performed by pressing in a hydraulic press with a cylindrical die with the hob diameter of $20 \mathrm{~mm} 2 \mathrm{~g}$ nanopowder batches were poured into the die and then compacted at the pressure of $3 \mathrm{t} / \mathrm{cm}^{2}$ for $10 \mathrm{~min}$ at room temperature. After that, the compacted material was extracted from the die. The thermal treatment of the consolidated samples was performed in the temperature range of 200-1000 ${ }^{\circ} \mathrm{C}$ using a Nabertherm R 120/1000/13/B180 (Nabertherm, Germany) furnace, and the roughing pump provided the pressure of at least $10^{-2} \mathrm{~mm} \mathrm{Hg}$.

2.3. The analysis of the characteristics of bimetallic nanoparticles and composites based on them

Electron microscopy analysis and the elementary analysis of bimetallic nanoparticles and consolidated samples was conducted using a JEM 2100 transmission electron microscope (JEOL, Japan) with X-max (an integrated EDS system by Oxford Instruments, United Kingdom) and a Quanta 200 3D (FEI, USA) scanning electron microscope with Pegasus (an integrated system of elementary and structural analysis by EDAX, USA).

Particle size distribution of $\mathrm{Fe} / \mathrm{Cu}$ nanoparticles was obtained from image analysis of TEM micrographs at a magnification of 50,000. The mean size of $\mathrm{Fe} / \mathrm{Cu}$ nanoparticles was determined by measuring 1500 nanoparticles.

The phase composition of the samples was researched using a Shimadzu XRD 6000 (Shimadzu, Japan) X-ray diffractometer with filtered CuKa radiation at $40 \mathrm{kV}$ and $30 \mathrm{~mA}$ in the scanning mode in the $2 \theta$ angle range from $\sim 40$ to $80^{\circ}$ and with a step of $0.02^{\circ}$. The qualitative analysis was performed using the PDF-2 Release 2014 database.

The microhardness of the consolidated samples was determined using a PMT-3 microhardness tester with the indenter load of $100 \mathrm{~g}$. The microhardness of each sample was determined from at least 20 measurements.

The relative density of the compacted samples $\left(\rho / \rho_{0}\right)$ was determined from the apparent density that was measured while taking into account the geometry and mass of the samples. The apparent density was based on the calculated theoretical density of the materials $\left(8.35 \mathrm{~g} / \mathrm{cm}^{3}\right)$ while taking into account the chemical composition (73 wt.\% Fe and 27 wt.\% Cu). The mass of the obtained samples was measured using an Acculab ALC-210d4 (Sartorius, USA) analytical balance with the accuracy of $0.0001 \mathrm{~g}$.

\section{Results and discussion}

Fig. 1 shows a characteristic image of $\mathrm{Fe}-28 \mathrm{wt} \% \mathrm{Cu}$ nanoparticles obtained by the electrical explosion with the particle size distribution curve. As seen from Fig. 1, the particles mostly have spherical shape and their distribution by size is close to log-normal. Average particle size is $\sim 66 \mathrm{~nm}$. Also, individual particles may be as large as 200-300 nm.

The research of the elementary composition of Fe-28 wt\% Cu powder samples has shown that all the researched particles contain iron and copper. The particles are mostly Janus-type structures (Fig. 2a, particle 1) and core-shell structures (Fig. 2a, particle 2). Such structures are characteristic for bimetallic nanoparticles obtained by this method [24].

Fig. 3 shows a raster image of the surface of a Fe- $28 \mathrm{wt} \% \mathrm{Cu}$ composite obtained by nanoparticle consolidation and the elementary composition of its surface. As seen from Fig. 3a, the sample mainly comprises nanosize particles, and large particles sized $>0.5 \mu \mathrm{m}$ are probably agglomerates of smaller particles. It ensues from Fig. $3 \mathrm{~b}$ and c that the metals (iron and copper) have highly homogeneous distribution throughout the samples volume.

Fig. 4 shows the results of X-ray diffraction analysis of the consolidated Fe-28 wt\% $\mathrm{Cu}$ samples depending on the annealing temperature. The initial sample at $25{ }^{\circ} \mathrm{C}$ contains the copper phase and $\alpha$ - and $\gamma$ phases of iron as well as ferric oxide $\mathrm{Fe}_{2} \mathrm{O}_{3}$. It is probable that high temperature $\mathrm{Y}$ - $\mathrm{Fe}$ is formed at over $1200{ }^{\circ} \mathrm{C}$ because of the high cooling rate of the disperse phase that is formed from the gas-plasma state [25]. 


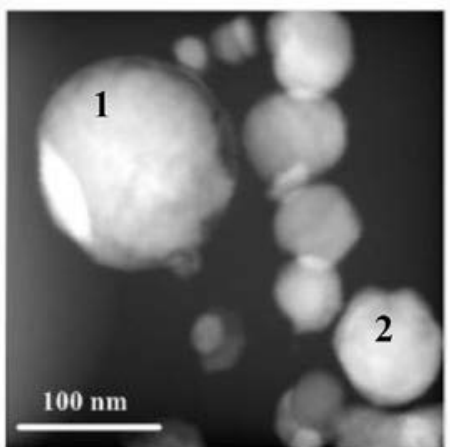

a

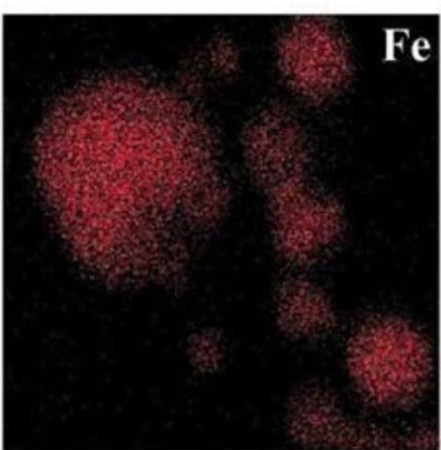

b

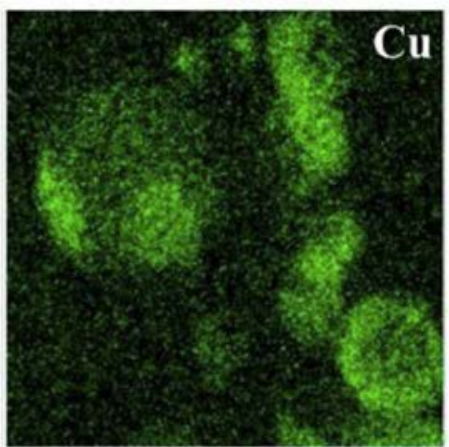

Fig. 2. TEM (a) and EDS (b, c) images of bimetallic Fee28Cu wt.\% nanoparticles: 1 - Janus nanoparticle, 2 - core-shell nanoparticle.

The parameter of the copper lattice determined from the locations of Bragg maxima is $3.608 \AA$. According to Vegard's rule, it corresponds to a copper-based solid solution with the content of iron about 2.4 at. \% [26]. Thus, when bimetallic particles are produced by electrical explosion, non-equilibrium phases are formed, as in the case with the mechanical activation of powders. The areas of coherent scattering were evaluated at 38 and $25 \mathrm{~nm}$ for iron and copper, respectively (Fig. 5a). We can note that the sum of these values is close to the average size of bimetallic nanoparticles $(66 \mathrm{~nm})$.

Heating the compacted sample to $200{ }^{\circ} \mathrm{C}$ leads to the decomposition of the copper-based solid solution and an $\gamma$ - $\alpha$ phase transition in iron. The lattice parameter takes the standard value of $3.615 \AA$. We observe an insignificant increase in the size of the areas of coherent scattering of iron $d_{\text {csr }}$ (Fig. 5a) and a decrease in lattice microstains $\varepsilon$ (Fig. 5b). Such changes may be a consequence of a decreased defects density and the relaxation of the crystalline lattice.

Heating the samples to $400{ }^{\circ} \mathrm{C}$ leads to a significant increase in $\mathrm{d}_{\text {csr }}$ of both copper and iron and a decrease in $\varepsilon$ of iron. Such changes in the diff raction diagram can speak in favor of sintering process start. This process leads to more intense migration of sub-boundaries and to the coalescence of crystallites while the sizes of $d_{c s r}$ increase. In accordance with Bochvar rule [27], copper (at $140 \div 270^{\circ} \mathrm{C}$ ) and iron (at $270 \div 450^{\circ} \mathrm{C}$ ) are characterized by the development of recrystallization that results in the formation of crystallites with a more equilibrium (defectless) structure.

When a sample is heated to $600^{\circ} \mathrm{C}$, a drastic decrease in $\mathrm{d}_{\mathrm{csr}}$ and $\varepsilon$ for copper is observed. These results suggest that at $600^{\circ} \mathrm{C}$, copper and iron crystallites with more equilibrium structure are formed. In the temperature range of $200-600^{\circ} \mathrm{C}$, ferric oxide $\mathrm{Fe}_{2} \mathrm{O}_{3}$ is observed in the samples. At $600-800{ }^{\circ} \mathrm{C}$, we see peaks that correspond to copper oxide in the sample, $\mathrm{Cu}_{2} \mathrm{O}$ (Fig. 4). As shown in Ref. [28], such a reaction can be observed in a Fe-Cu-O system if liquid copper interacts with iron oxide that is formed in the oxidized surface layer of nanoparticles with iron shell (Fig. 2).

Increasing annealing temperature to $800{ }^{\circ} \mathrm{C}$ does not result in a significant increase in the values of $\mathrm{d}_{\mathrm{csr}}$ and $\varepsilon$. For iron we observe an increase in $d_{\text {csr }}$ and a decrease in $\varepsilon$. Here the peak corresponding to iron oxide disappears and the maximum corresponding to copper oxide increases (Fig. 4). This suggests that iron oxide has been fully reduced by copper.

Fig. 6 shows an evolution of the microstructure of consolidated samples when they are sintered in vacuum in the temperature range of 200-800 ${ }^{\circ} \mathrm{C}$. Because of the lower coefficient of reflection of electrons by iron, the areas saturated with copper look lighter in Fig. 6c and $d$ and therefore can be easily identified.

At $200{ }^{\circ} \mathrm{C}$ (Fig. 6a), as compared to the initial sample (Fig. 3a), no significant changes in the microstructure are visually observed. However, the relative density of the sample $\mathrm{p} / \mathrm{p}_{0}$ (Fig. 7) is increasing. The density increase can probably be attributed to low-temperature sintering of copper nanoparticles as copper has a lower melting temperature than iron. The ff ect of low-temperature sintering and melting of nanoparticles is well-known $[29,30]$ and is attributed to their surface energy [31] which is determined by a high density of defects and the curvatures of nanoparticles surface [32]. It is also shown in Ref. [33] that sintering of $\mathrm{Cu}$ nanoparticles (average size of $20 \mathrm{~nm}$ ) obtained by the electrical explosion of copper wire takes place in the temperature range of $170-270{ }^{\circ} \mathrm{C}$. According to [34], sintering of copper nanoparticles (with the average size of $23 \mathrm{~nm}$ and covered in $\sim 1 \mathrm{~nm}$ carbon shell) obtained by the electrical explosion of copper wire was observed already at $\sim 200^{\circ} \mathrm{C}$.

The analysis of the relative density of the samples has shown that after sintering in the temperature range of $200-400{ }^{\circ} \mathrm{C}$, the relative

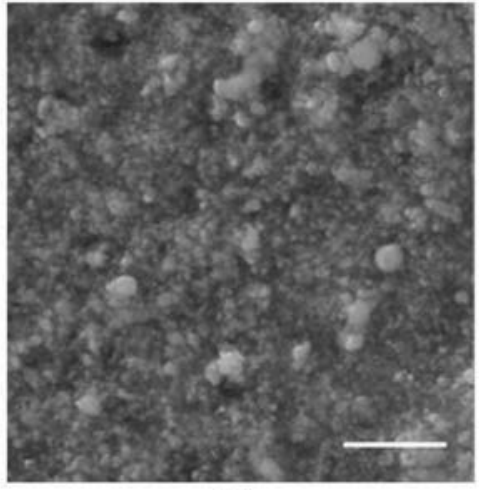

(a)

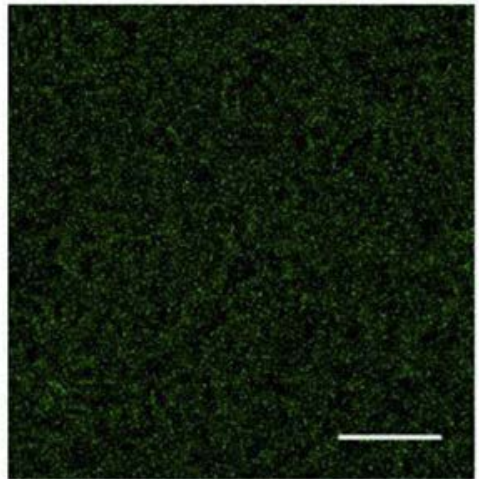

(b)

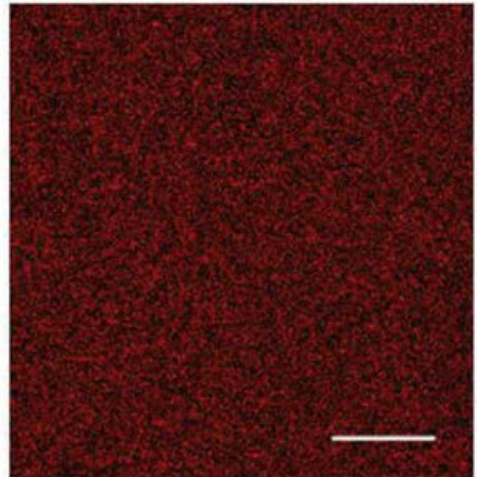

(c)

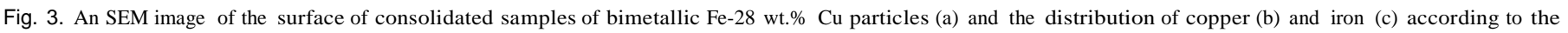
SEM-EDS analysis in the mapping mode. All bars $2 \mu \mathrm{m}$. 


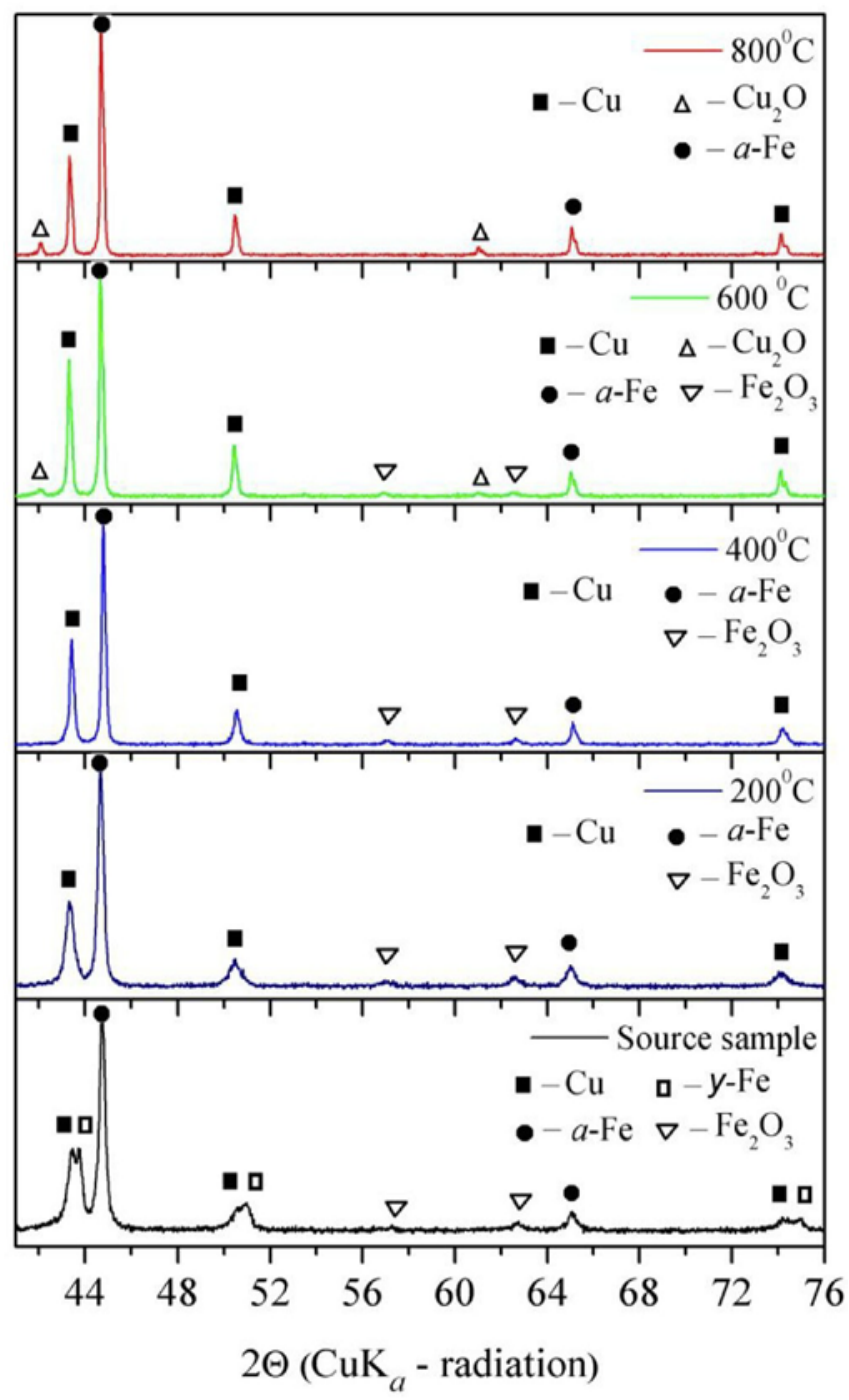

Fig. 4. The diff raction diagrams of the consolidated Fee28Cu wt.\% samples depending on the temperature.

density continues increasing. The size of the particles in the sample obtained at $400{ }^{\circ} \mathrm{C}$ is significantly higher than the size of the grains in the sample obtained at $200{ }^{\circ} \mathrm{C}$ (Fig. 6b), which suggests that nanoparticles merge (create agglomerates) when the temperature grows.

In the range of annealing temperatures $\left(400-600^{\circ} \mathrm{C}\right)$, the process of copper and iron particles sintering is taking place more intensely. As a result, the density of the sample increases (Fig. 7). At $600{ }^{\circ} \mathrm{C}$ the structure of the sample significantly differs from the structure of the samples obtained at lower temperatures (Fig. 6c). In the sample, we see separated areas of copper and iron that are in contact with each other. Here, areas saturated with iron normally have round shape and are $2-5 \mu \mathrm{m}$ in size; they are surrounded by areas of copper that are lightercolored and spread along the boundaries (Fig. 6). Also, there are large irregularly shaped pores in the sample. Based on the fact that at $600{ }^{\circ} \mathrm{C}$, the value of $d_{c r r}$ for both copper and iron is less than that at $400{ }^{\circ} \mathrm{C}$, we can suppose that in the temperature range of $400-600{ }^{\circ} \mathrm{C}$, material consolidation will take place through the liquid phase. Inside large micron-sized areas saturated with iron, light-colored round-shape areas of copper depositions are observed. Those are less than $1 \mu \mathrm{m}$ in size (Fig. 6c and d), and this resembles what we see in Ref. [35] happening with a $\mathrm{Cu}_{80} \mathrm{Fe}_{20}$ alloy in areas saturated with iron $\left(\mathrm{C}_{\mathrm{Fe}} \sim 77 \%\right)$. This also confirms that a liquid-phase separation of copper and iron is taking place in the specified conditions.

After annealing at $800{ }^{\circ} \mathrm{C}$, further compaction of the sample during sintering takes place (Fig. 7). As a result, pore size is significantly decreased. In the material we mostly see isolated pores with a shape that is close to sphere (Fig. 6d). The separation of metallic phases becomes more apparent. In the meanwhile, despite the fact that in the initial powders there is less copper than iron, the areas that contain iron are normally surrounded with areas containing copper. Here, the value of $\varepsilon$ for the iron component continues decreasing. In our opinion, this means that at $800{ }^{\circ} \mathrm{C}$ rebuilding of the crystalline structure of iron grains is not completed. According to data in Ref. [36], the growth of the relative density of the samples produced from iron nanoparticles with the initial size of $38 \mathrm{~nm}$ continues up to $900{ }^{\circ} \mathrm{C}$. Annealing of the samples obtained by particle consolidation at $800{ }^{\circ} \mathrm{C}$ and above leads to the formation of a stable $\mathrm{Fe}-28 \mathrm{wt} \% \mathrm{Cu}$ composite with even distribution of the components throughout the volume (Fig. 8).

A measurement of the microhardness of the compact samples has shown that it significantly increases (from 0.5 to $2.6 \mathrm{GPa}$ ) after annealing in the range of $200-600^{\circ} \mathrm{C}$ (Fig. 9). As it has been shown above, in this temperature range, copper and iron sintering processes are developing. Also, there is a linear dependency when the relative density of the composite is increasing along with the temperature (Fig. 7). The microhardness attained after annealing at $600{ }^{\circ} \mathrm{C}$ is close to the value observed in Ref. [37] for an alloy of similar composition (Fe-15\% Cu) with a nanocrystalline structure $(\mathrm{d} \sim 15 \mathrm{~nm})$. That alloy has been obtained by high-pressure torsion that caused high degree of deformation (e $>100)$. In the above referenced paper, as well as in our research, at this temperature $\left(600{ }^{\circ} \mathrm{C}\right)$ noticeable roughing of the structure is observed. However, the size of $\mathrm{Cu}$ and Fe particles remains significantly smaller $(150-200 \mathrm{~nm})$. Despite a significantly larger size of the
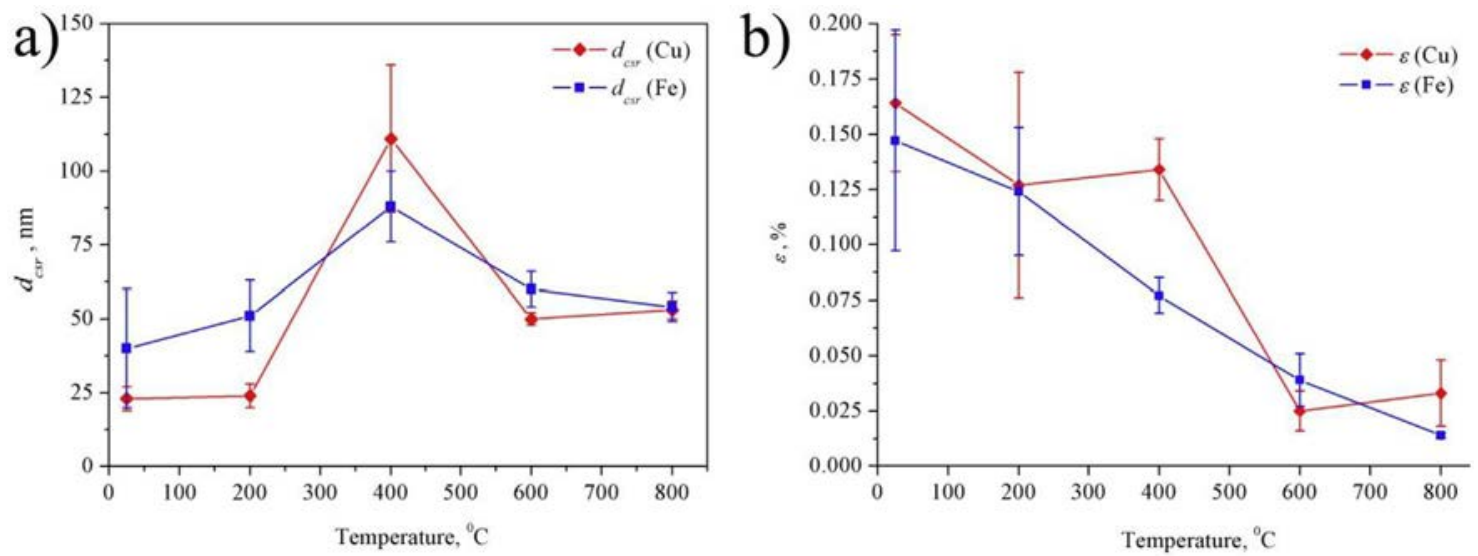

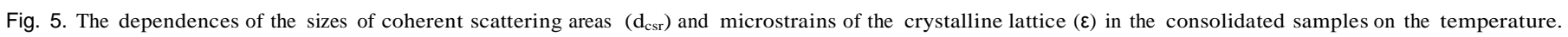




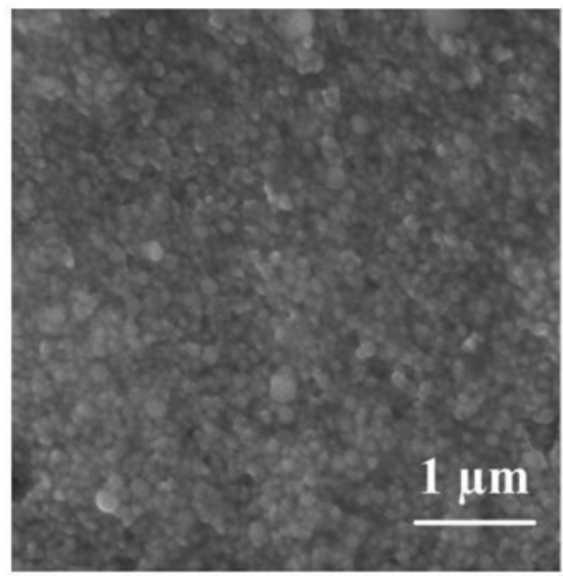

(a)

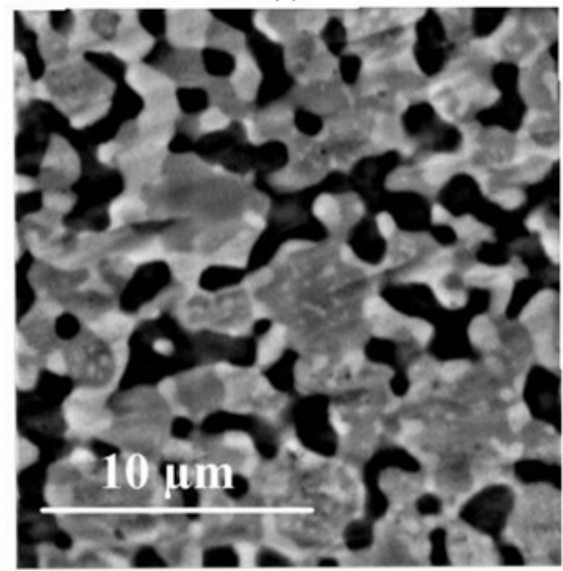

(c)

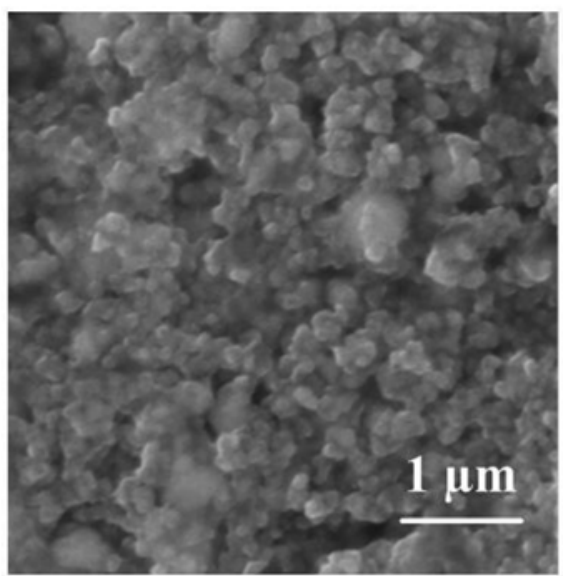

(b)

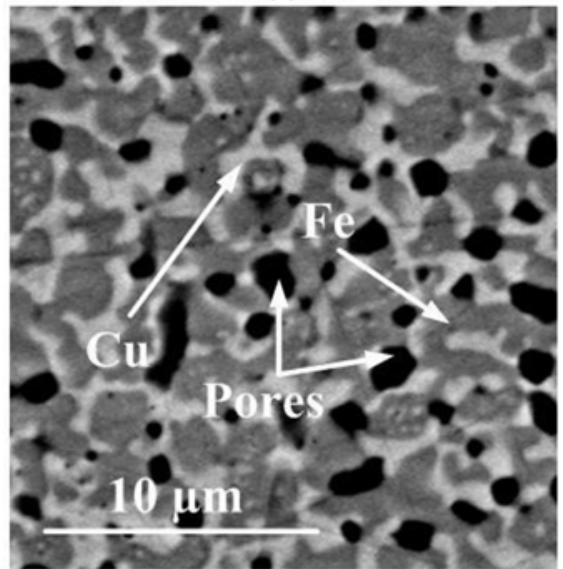

(d)

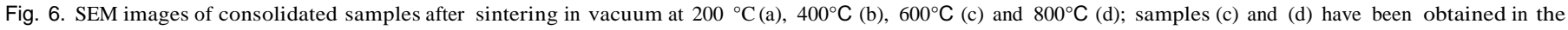
reflected electrons mode.

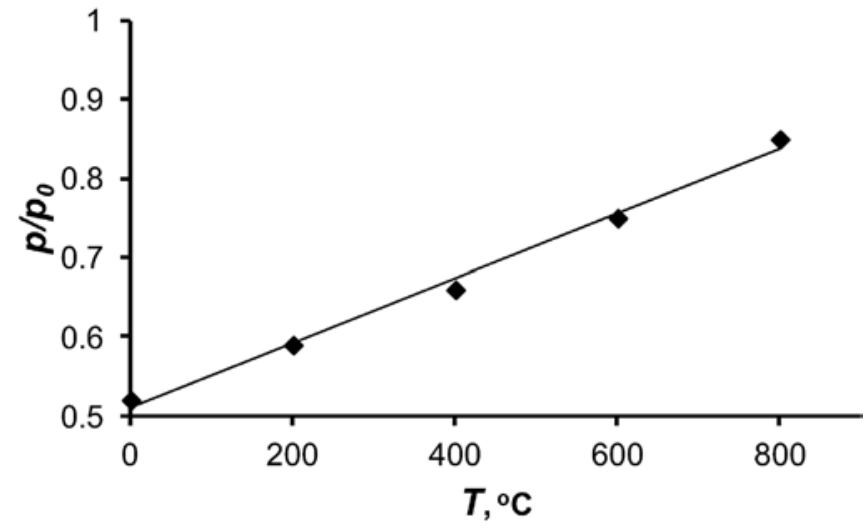

Fig. 7. The dependency of the relative density of consolidated Fe- $28 \mathrm{wt} \% \mathrm{Cu}$ samples on the sintering temperature: $\mathrm{p}$ - measured density, $\mathrm{p}_{0}$ - theoretical density.

structural elements, high strength properties of the composite obtained from bimetallic particles can be the result of the formation of a heterogeneous structure. Further increase in the annealing temperature up to $800^{\circ} \mathrm{C}$ leads to an insignificant decrease in the microhardness of the analyzed material (Fig. 9).

Thus, our research has shown that as a result of the compaction of bimetallic nanoparticles obtained by electrical explosion, a Fe-28 wt\% $\mathrm{Cu}$ composite is formed, in which the elements are homogeneously distributed throughout the volume. As a result of annealing of the consolidated samples in the temperature range of $200-400{ }^{\circ} \mathrm{C}$, the processes of low-temperature sintering of copper and iron are developing. When the annealing temperature increases to $600{ }^{\circ} \mathrm{C}$, two phenomena are observed: liquid-phase separation of copper and iron and the formation of areas saturated with iron that are separated by areas containing copper along the separation boundaries. Inside the areas saturated with iron, round-shaped depositions of copper with the size below $1 \mu \mathrm{m}$ are found. Such a hierarchically arranged structure remains stable when the annealing temperature is below $800^{\circ} \mathrm{C}$. This, in combination with the deposition of iron and copper oxides, promotes a significant increase in the strength properties of the $\mathrm{Fe}-28 \mathrm{wt} \% \mathrm{Cu}$ composite. Throughout the entire range of annealing temperatures that we analyzed, a linear increase in the relative density (i. e. a decrease in the porosity) of the composite is observed when the temperature is increased.

\section{Conclusion}

In this research paper, we suggest a new method of producing a Fe$28 \mathrm{wt} \% \mathrm{Cu}$ composite by compacting and subsequent sintering bimetallic nanoparticles made of metals of limited mutual miscibility (iron and copper) and obtained by the electrical explosion of two intertwined wires. It has been shown that as a result of such treatment, a Fe-28 wt\% $\mathrm{Cu}$ composite with the homogeneous distribution of elements throughout its volume is formed. Heating the consolidated samples in the temperature range of $200-400{ }^{\circ} \mathrm{C}$ induce the processes of lowtemperature sintering of copper and iron. When the temperature is increased to $600{ }^{\circ} \mathrm{C}$, two phenomena are observed: liquid-phase 


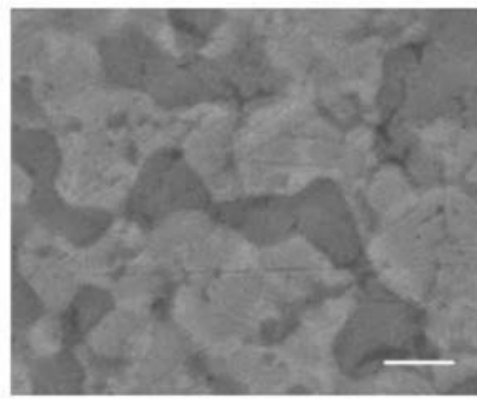

a

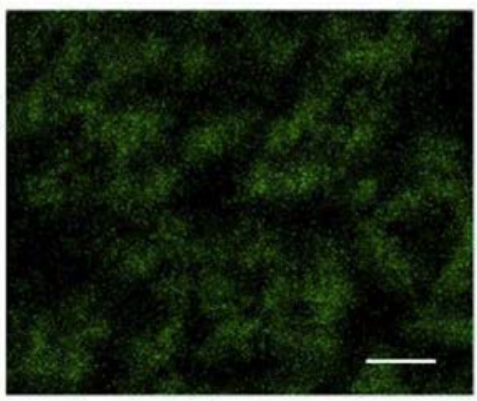

b

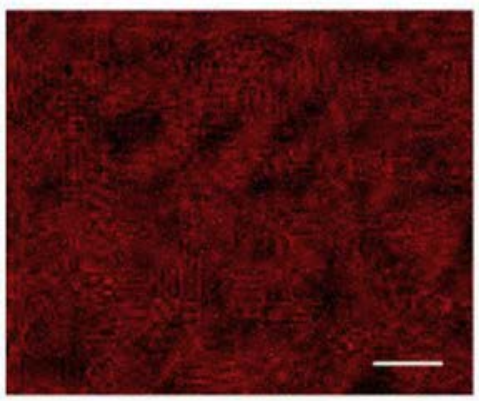

C

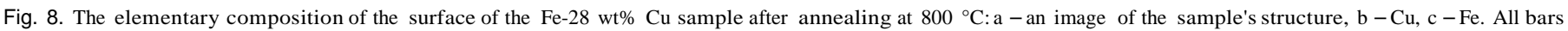
$2 \mu \mathrm{m}$.

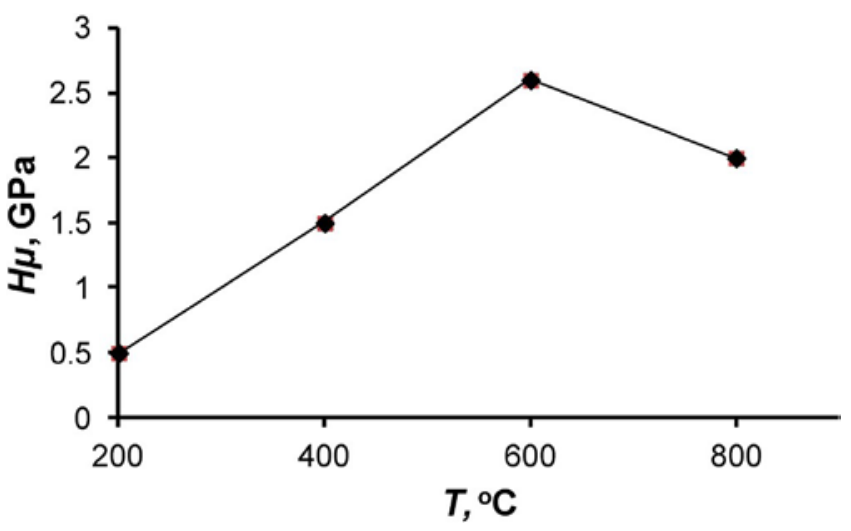

Fig. 9. The dependency of the Fee28Cu wt.\% samples microhardness on the annealing temperature.

separation of copper and iron and the formation of areas saturated with iron that are separated by areas saturated with copper along the separation boundaries. Inside the areas saturated with iron, round-shaped depositions of copper with the size below $1 \mu \mathrm{m}$ are found. In the entire analyzed range of annealing temperatures, an even increase in the relative density (i. e. a decrease in the porosity) of the composite is observed when the temperature is increased. The consolidation of bimetallic Fe-28 wt\% Cu nanoparticles and their subsequent sintering allows for obtaining volumetric composites with homogeneous structure without distinct macroscopic separation of phases and with high strength characteristics.

\section{Acknowledgments}

The research leading to the results reported in the present paper has received funding from Russian Science Foundation (Grant No 17-1901319).

\section{References}

[1] X. Sauvage, P. Jessner, F. Vurpillot, R. Pippan, Scripta Mater. 58 (12) (2008) 1125-1128.
[2] S. Bose, V. Bhattacharya, K. Chattopadhyay, P. Ayyub, Acta Mater. 56 (2008) 4522.

[3] E. Ma, Prog. Mater. Sci. 50 (4) (2005) 413-509.

[4] N.F. Shkodich, A.S. Rogachev, A.S. Mukasyan, D.O. Moskovskikh, K.V. Kuskov, A.S. Schukin, N.Y. Khomenko, Russ. J. Phys. Chem. B 11 (1) (2017) 173-179.

[5] C. Wu, M. Li, P. Jia, R. Liu, S. Cui, H. Geng, J. Alloy. Comp. 688 (2016) 18-22.

[6] I. Ohnuma, T. Saegusa, Y. Takaku, C.P. Wang, X.J. Liu, R. Kainuma, K. Ishida, J. Electron. Mater. 38 (1) (2009) 2-9.

[7] D.P. Shen, Y.J. Zhu, X. Yang, W.P. Tong, Vacuum 149 (2018) 207-213.

[8] A.K. Shukla, S.N. Murty, S.C. Sharma, K. Mondal, J. Alloy. Comp. 590 (2014) 514-525.

[9] A.R. Yavari, P.J. Desre, T. Benameur, Phys. Rev. Lett. 68 (1992) 2235.

[10] Y.P. Xie, S.J. Zhao, Comput. Mater. Sci. 50 (2011) 2586-2591.

[11] J.W. Jeon, Synthesis, Microstructure, and Mechanical Behavior of Fe-cu Composites, Master's Thesis University of Tennessee, 2005.

[12] P. Gorria, D. Martinez-Blanco, R. Iglesias, S.L. Palacios, M.J. Perez, J.A. Blanco, L. Fernandez arquin, A. Hernando, M.A. Gonzales, J. Magn. Magn Mater. 300 (2006) 229-233.

[13] H. Zhang, W. Chu, H. Xu, J. Zhou, Fuel 89 (2010) 3127.

[14] S.R. Yan, K.W. Jun, J.S. Hong, M.J. Choi, K.W. Lee, Appl. Catal. Gen. 194 (2000) 63.

[15] W.U.H. Syed, A.J. Pinkerton, Z. Liu, L. Li, Appl. Surf. Sci. 253 (2007) 7926.

[16] Y. Li, X. Qu, Z. Zheng, C. Lie, Z. Zou, S. Yu, Int. J. Refract. Metals Hard Mater. 21 (2003) 259.

[17] N.A. Luechinger, R.N. Grass, E.K. Athanassiou, W.J. Stark, Chem. Mater. 22 (1) (2009) 155-160.

[18] M. Rabiee, H. Mirzadeh, A. Ataie, Adv. Powder Technol. 28 (2017) 1882-1887.

[19] E. Ma, J.-H. He, P. Schilling, Phys. Rev. B 55 (1997) 5542.

[20] J. Eckert, J. Holzer, C. Krill iII, W.L. Johnson, J. Appl. Phys. 73 (1993) 2794-2802.

[21] M.I. Lerner, S.G. Psakhie, A.S. Lozhkomoev, A.F. Sharipova, A.V. Pervikov, I. Gotman, E.Y. Gutmanas, Adv. Eng. Mater. 1701024 (2018).

[22] A. Kocjan, M. Logar, Z. Shen, Sci. Rep. 7 (1) (2017) 2541.

[23] K.H. Kim, H.C. Youn, C.J. Choi, B.T. Lee, Mater. Lett. 61 (2007) 1218-1222.

[24] M.I. Lerner, A.V. Pervikov, E.A. Glazkova, N.V. Svarovskaya, A.S. Lozhkomoev, S.G. Psakhie, Powder Technol. 288 (2016) 371-378.

[25] Y. Kotov, Nanotechnol. Russia 4 (2009) 415-424.

[26] V.A. Lubarda, Mech. Mater. 35 (2003) 53-68.

[27] N.F. Kazakov, Pergamon Press 304 (1985).

[28] D. Shishin, T. Hidayat, E. Jak, S.A. Decterov, Calphad Comput. Coupling Phase Diagrams Thermochem. 41 (2013) 160-179.

[29] M. Zhang, M.Y. Efremov, F. Schiettekatte, et al., Phys. Rev. B 62 (15) (2000) 10548-10557.

[30] K. Ida, Y. Sugiyama, Y. Chujyo, M. Tomonari, T. Tokunaga, K. Sasaki, K. Kuroda, J. Electron. Microsc. 59 (2010) S75-S80.

[31] Q. Jiang, S.H. Zhang, J.C. Li, Solid State Commun. 130 (9) (2004) 581-584.

[32] E.K. Yu, L. Piao, S.H. Kim, Bull. Kor. Chem. Soc. 32 (2011) 4099-4102.

[33] J. Mittal, K.-L. Lin, Mater. Char. 109 (2015) 19-24.

[34] C. Kim, G. Lee, C. Rhee, M. Lee, Nanoscale 7 (2015) 6627-6635.

[35] S. Liu, J. Jie, B. Dong, Z. Guo, T. Wang, T. Li, Mater. Des. 156 (2018) 71-81.

[36] D. Sivaprahasam, A.M. Sriramamurthy, S. Bysakh, G. Sundararajan, K. Chattopadhyay, Metall. Mater. Trans. 49 (4) (2018) 1410-1424.

[37] A. Bachmaier, M. Kerber, D. Setman, R. Pippan, Acta Mater. 60 (2012) 860-871. 